\title{
5 \\ Core knowledge in a professional discipline of public management
}

Marshall: We've decided to assign Chapter 4 of the book to students on the course. What questions do we want to ask students to be prepared to discuss in class?

Nora: We should probably start with concept identification questions.

Petra: That sounds like a good idea. We'll serve them up - then Marshall will have to answer them!

Marshall: Go for it.

Olivier: I've got an easy one. What's a public organization?

Nora: That's easy?

Marshall: I'll make it easy by dividing my response into two parts: what are public organizations for, and what do they consist in. Within purposive theorizing of the professional discipline of public management, public organizations are for creating public value. Public organizations consist in enterprise functions not least, management and program delivery - and the mechanisms that perform them. Such mechanisms are theorized as processes, with the main form being scenario-processes. The outcomes of scenario-processes play pivotal roles in how mechanisms work in performing enterprise functions. Scenario-process outcomes eventuate from scenario-process activities. Such activities partly consist in the lines of action of individuals, as they interact with one another within contexts that reflect the outcome of earlier scenario-processes. Thus, public organizations are purposeful phenomena that effectuate the creation of public value through the performance of enterprise functions, which, in turn, is accomplished by a multitude of scenario-processes and their context-activity-outcome dynamics, within which individual lines of action have a significant role to play. Petra: That's pretty abstract, Marshall, but I can see how it pulls together points that were made in different segments of the audio-guide presentation.

Nora: Doesn't this answer beg a lot of questions?

Marshall: Surely it does, but not just because it is abstract and brief. It's also because practical arguments like this are always incomplete, as Aristotle pointed out in his theory of rhetoric. But fire away if you want to pose questions that this particular statement begs.

Nora: You present the mechanisms within public organizations as scenario- 
processes, but indicate that scenario-processes aren't the only form of mechanism. I vaguely remember there being another form. What is it?

Olivier: It's a conversion-process. I remember that conversion-processes result in outputs, whereas scenario-processes result in outcomes. Also, conversionprocess activities are fed by inputs, while scenario process activities are channeled by context.

Petra: I understand that these pure types of mechanisms can be combined - as when an operating IT system - a conversion-process - is part of a management control system - a scenario-process.

Nora: Let's move on. Here's another easy question: what's management?

Marshall: In keeping with classical purposive theorizing of enterprises, management is a function within public organizations. If this function is not adequately performed, then the effectuation of public value creation will be adversely affected. Deficits in the management function's performance ramify in the inadequate performance of other functions, such as program delivery and system development. The issue, then, is what mechanisms perform the management function. Turning again to classical purposive theorizing of enterprises, an authoritative answer is planning, directing, coordinating, and controlling. These four mechanisms are alike in two ways: they have a role to play in performing the management function and they mainly consist in scenario-processes, with their particular context-activity-outcome dynamics. The lines of action of individuals are constitutive of scenario-process activity.

Petra: A lot of practitioners would say that planning, directing, coordinating, and controlling are management functions, but you refer to them as mechanisms. Since functions and mechanisms are not the same ideas, somebody has to be wrong. Am I right?

Marshall: It's a neat question. I'll take your word for it that it's common to say that planning, directing, coordinating, and controlling are functions. If you want to label planning, directing, coordinating, and controlling as functions, then please think of them as constitutive functions of the management function of public organizations. The idea that a given function has constitutive functions is not unknown to science; in anatomy, breathing is a constitutive function of respiration. Similarly, the idea that functions have constitutive functions is also not unknown to engineering design, with constitutive functions typically labeled as sub-functions. But many professional practitioners of public management aren't familiar with models that present constitutive descriptions of natural and purposeful phenomena, and many aren't very practiced in mechanism-intent thinking. So, we face a challenge as educators. The imperfect solution is to stick to one basic vocabulary, specifically, my patterned language of purposive theorizing. And in the pattern language, management (like respiration) is a function, whereas planning, directing, coordinating, and controlling (like breathing) are mechanisms. So, Petra, nobody's wrong, but rather we just don't have aligned vocabularies.

Petra: Isn't that a problem, Marshall?

Marshall: If you say so, it is. But break it down. One problem is that people may not know how to engage in mechanism-intent style purposive theorization of 
public organizations and professional practice. Here, the solution is show them how and why to do it. Another problem is that people may not know how to use purposive theorizing in professional practice. Here, the solution is to show them how to do that. The common solution to both parts of the problem is education. That overall solution implies that people like us should dramatize the design-oriented professional discipline of public management and our roles as educators, so we can teach them what they need to learn.

Petra: So, how can I explain the idea of management to someone who's confused about the vocabulary of function and mechanism?

Marshall: A professional practitioner needs to be able to present their thinking as to whether and how a specific public organization's mechanisms for performing the management function are adequate. As they present their thinking, they should identify what they consider to be the conceptual design of the management function, if they are focusing on it. In representing the management function's conceptual design, they might say that the planning function enables the directing function, which, in turn, enables the coordinating and controlling functions, and so on. As they present their thinking, they should also identify what they consider to be the management function's embodiment design. In representing the embodiment design, they should identify the mechanisms for performing management's constitutive functions. In explaining how the management function is actually performed, they should drill-down into the mechanisms' context-activity-outcome dynamics and/or their input-activityoutput dynamics, and they should then make an argument about the functional relation between the embodiment design, fleshed out in these terms, and the management function's conceptual design, which is what an embodiment design effectuates.

Petra: And what would you say if people don't get this idea?

Marshall: Like any other educator, I would present an analogy. I have found that an anatomical analogy usually works well. I point out that the conceptual design of a living body includes respiration and its constitutive breathing function. This conceptual design is effectuated by a body's embodiment design, which consists in a mechanism for breathing. This mechanism includes the cyclical activities of inhaling and exhaling, each involving their inputs (i.e., gases contained in air) and outputs (e.g., retained oxygen and released carbon dioxide). I joke that it's great that your body's embodiment design is adequate to its conceptual design, because otherwise you wouldn't be able to take in my explanation. If I have time, I complement this line with an analogy involving a physical machine, specifically a jug whose conceptual design involves removal of unwanted dissolved elements from tap water prior to drinking it and whose embodiment design involves a downward flow of water through a filtering unit and then into a portable basin. I keep a Brita filter jug in my office for this purpose.

Petra: I'm satisfied, let's move on.

Olivier: I'm ready to move down to the mezzanine level of the Gallery: what's a design-project?

Marshall: A design-project is a mechanism to perform the enterprise functions of public organizations, whether the management function or otherwise. 
A design-project consists in two, interlocking, scenario-processes: designing and decision-making. Both are needed if a public organization is going to solve a "new" problem, or solve an "old" problem in a novel manner. Without designing, nothing novel can be done; without decision-making, nothing will change in how the organization's functions are performed. Stated in systems terms, a design-project's scenario-processes are, in multiple ways, interlocking. For example, an intermediate outcome of decision-making is typically to initiate the front-end stage of a design-project. As another example, the intermediate outcomes of designing constitute the initial conditions of decision-making, as, for example, when decision-making takes the specific form of a milestone or gateway project review. The designing scenario-process ultimately eventuates in object designs and realization plans, while the decision-making scenario-process ultimately eventuates in authoritative instructions to implement the realization plans for the object design. Nora: If you wanted to add just another level of detail to this answer, what would you say?

Marshall: Well, I would want to say more about the initiation of a project's frontend stage and about project reviews. I'd also want to say more about designing and decision-making viewed in isolation from one another, by adding depth to the discussion of their respective context-activity-outcome dynamics. In discussing designing, I'd want to draw on Nigel Cross' ideas about problem- and solution-structuring. In discussing decision-making, I'd want to draw on Sandra Marshall's ideas about sense-making, Charles Tilly's ideas about argumentation, and Erving Goffman's ideas about dramatization.

Olivier: Well, then, the obvious next concept to identify is professional activities. Marshall: As a collection, professional activities are constitutive of mechanisms that effectuate design-projects or that otherwise perform enterprise functions of public organizations. Within this collection are the professional activities of sense-making, designing, argumentation, and dramatization. Each professional activity is a scenario-process. The activity aspect of such scenario-processes consists in interactions among individuals. These interactions are, in turn, constituted by individual lines of action. Such lines of action are constituted, in turn, by talk and gestural moves.

Olivier: Is it correct to say that professional activities are individual-level phenomena in public organizations?

Marshall: I understand why you might think so, given that individual lines of action are constitutive of the scenario-processes that I conceive as professional activities. The answer to your question is, nevertheless, no. Public organizations are theorized here as purposeful phenomena. In providing a purposive theory of public organizations, I draw on precedents in management thought, ${ }^{1}$ program planning and evaluation, ${ }^{2}$ functional biology, ${ }^{3}$ engineering design, ${ }^{4}$ processual sociology, ${ }^{5}$ and process philosophy. ${ }^{6}$ None of these precedents is closely aligned with the idea that social phenomena are best theorized as hierarchically-stratified systems.

Petra: You lost me with some of these theoretical references, Marshall. Let me ask a yes/no question: are professional activities what individuals do in public organizations? 
Nora: Petra, if I can jump in, it's an understandable issue, but it's not a yes/no question. What individuals do is constitutive of professional activities; therefore, your statement is correct, but one could equally argue that professional activities consist in what goes on among individuals. Argumentation - representing ideas to others so that they understand and respond to them - is an inherently multiperson process. So is dramatization, for essentially the same reason. Designing is inherently multi-disciplinary and is therefore multi-person in nature. The only professional activity that might not be inherently multi-person is sense-making, but even here the scenario-process outcome in a public organization might be a declared, collective situational orientation. If these qualifications are important to emphasize, then I think that "no" is a better answer than "yes." Right, Marshall? Marshall: Yes, Nora, except that if one says "no" to Petra's question, without having provided any background, the questioner will think you must be a pointyhead academic. This is not an impression we should leave.

Nora: How about we ask them to discuss the relationship between concepts?

Olivier: That's an idea. How about the relation between strategic planning and the strategic triangle?

Marshall: These ideas figure in purposive theorizing about public organizations, not least in the work of John Bryson and Mark Moore. As far as professional practice is concerned, strategic planning and the strategic triangle are both relevant to formulating conceptual designs for public organizations; specifically, they add depth to such representations as they concern the management function. Bryson presents strategic planning as being for making fundamental decisions about the future of public organizations. Moore presents the strategic triangle as being for creating and assessing a public organization's strategy. In line with mechanismintent theorizing, strategic planning and the strategic triangle are compatible ideas about a public organization's management function: Creating and assessing a public organization's strategy enables making fundamental decisions about a public organization's future.

Let's add some depth to this purposive theorizing by sketching a generic embodiment design for performing the management function. As part of an embodiment design, strategic planning is a mechanism for performing the constitutive management functions of planning and directing. Following Bryson and, more so, Barzelay and Campbell, strategic planning - as a mechanism - is specifically a design-project. As such, strategic planning projects are constituted by the scenario-processes of designing and decision-making.

Designing and decision-making are interlocking mechanisms. The designing mechanism within strategic planning projects eventuates in (novel) objects, whereas the decision-making mechanism eventuates in (fresh) decisions. The objects may be labeled as visions, alternative futures, planning options, and the like. The decisions may be communicated in documentary form and/or dramatized through performances during stage-managed events.

An embodiment design for strategic planning projects would typically include multi-person activities. Such activities would typically occur within a dynamically stable (though not stationary) project context, an effect of which is to certify various participants as agents of the organization's strategic planning. 
This sketch of the generic embodiment design of strategic planning projects can be made more granular - for example, by typifying the professional activities of sense-making, designing, and argumentation, as they relate to such projects. Nora: Marshall, are you stopping there? I thought you were going to talk about how Moore's strategic triangle can be incorporated into strategic planning projects.

Marshall: I paused only to make sure that you all are actively listening. Clearly that's the case, at least with you, Nora.

Petra: Keep going, Marshall.

Marshall: Relating the strategic triangle to strategic planning is challenging because Moore's purposive theory of strategic management in government has almost none of the features of strategic planning as this idea was just sketched out. Nevertheless, we can spot two points of contact between strategic planning projects and the strategic triangle, working with the generic embodiment design sketched above.

First, we can place the strategic triangle within the designing part of strategic planning projects. As an established tool for generating novel strategic planning objects, the strategic triangle would channel the activity within the designing scenario-process. In Moore's terms, a "strategy" would be such an object. As such, the strategic triangle could give some specificity to the "content" of objects that eventuate from the designing scenario-process within strategic planning projects.

Second, we can place the strategic triangle within the professional activities "layer" of the generic embodiment design for strategic planning. It certainly can be used to channel sense-making, designing, argumentation, and dramatization activities. For instance, the triangle corners for "support" and "capacity" are plainly relevant for sense-making, while the triangle corners for "value" and "capacity" are plainly useful for designing. The triangle as a whole is undeniably useful for argumentation, as it can give structure to the giving of reasons about shifts in a public organization's strategy. And, if an audience knows about the strategic triangle, it can be a useful prop in a stage-managed dramatic presentation about a public organization's strategy.

Nora: That interpretation of Moore in relation to professional activities and strategic planning projects is actually quite cool, Marshall. It would be a good point to make in an exam. With that thought in mind, how would you conclude a short essay on strategic planning and the strategic triangle, if you were going for full marks?

Marshall: The challenge has been received, Nora. Here it goes: the intent of strategic planning projects is to make fundamental decisions about the future of a public organization. Strategic planning projects are mechanisms for performing a public organization's management function, especially its constitutive functions of planning and directing. The strategic triangle can surely be used to channel activities within the designing scenario-process of strategic planning projects; its use would be reflected in the objects that eventuate from such scenario processes. Depending on circumstances, the strategic triangle might also be used within the decision-making scenario-process of strategic planning 
projects. The idea of how the strategic triangle can be used in strategic planning can be fleshed out by adding specificity to the collection of professional activities within a generic embodiment design for strategic planning projects, where this collection consists in sense-making, designing, argumentation, and dramatization.

Nora: Well, I'll give you high marks for that, Marshall.

Olivier: I'd like to raise the bar even further by asking you to connect the dots between three ideas within the purposive theorizing about public management, one from each layer of the Gallery. The three are: management, designing, and dramatization.

Marshall: If you can connect the management and designing dots, Olivier, I'll be glad to connect those dots with dramatization.

Olivier: I'll give it a go, Marshall. As for management, it's a function within public organizations, considered as enterprises, in accord with Fayol's theorizing of enterprises in his classic book, General and Industrial Management. Public organizations, in turn, are for creating public value, in accord with Moore's wellestablished book, Creating Public Value: Strategic Management in Government. ${ }^{7}$ Putting these points together, management is a critical function within public organizations for effectuating public value creation; this point is entirely clear in Bryson's Strategic Planning for Public and Non-profit Organizations, ${ }^{8}$ as well as in publications of others in the field.

Marshall: So far so good, Olivier. Please continue.

Olivier: In accord with Simon's Sciences of the Artificial, ${ }^{9}$ designing is for creating novel mechanisms in response to an enterprise's challenges. A mechanism for responding to such challenges is design-projects. Designing is a constitutive process within such mechanisms, as is decision-making. Designing eventuates in object designs; in concept, these outcomes are "novel mechanisms" that resolve an enterprise's challenges, provided that they come to be approved for realization and utilization.

Marshall: So, we now have a fix on two dots; can you now connect them up?

Olivier: These ideas connect in two ways. Let's take the case where the "object design" eventuating from a designing scenario-process is meant to perform a public organization's management function; illustrations are a modified management control system and a new strategic plan. Here, designing is a way to respond to the challenges of a public organization's management function.

Marshall: That's straightforward. Please continue.

Olivier: Let's take the case where a design-project's front-end stage has started; illustrations are beginnings of strategic planning projects, or beginnings of system development projects. According to van Aken, a design-project's frontend stage will have been preceded by its fuzzy front-end stage, during which a challenge had been recognized and decisions made, the effect of which was to both establish the context of the design-project and to set its activities in motion. What happened during the project's fuzzy front-end stage arguably performed the enterprise's management function.

Marshall: Nice distinction, Olivier. Nevertheless, I'll stick to your first case when trying to connect these dots to dramatization. 
Olivier: That's fine.

Marshall: Does anyone want to say anything about the "dramatization" dot, before I start to make the connection?

Petra: Well, I think practitioners can immediately relate to the idea that putting on a show is a big part of any professional's work-life. It's what we do whenever we make a presentation or participate actively in a meeting. There's more to our practice than giving reasons for views on issues; we always have to foster impressions about who we are in the situation at hand and how we stand in relation to others who are there with us. Fostering the impressions we intend doesn't always work. But we have to try, for all sorts of reasons. Some of those reasons are obvious, like decisions aren't made on the basis of information and argument.

Marshall: I've also found that practitioners pick up on many of the ideas in Goffman's dramaturgical theory of social processes more readily - and acutely than with many other theoretical ideas. With that in mind, would you like to make a dramatization dot connection, Petra?

Petra: Well, let's run with the idea that designing is a scenario-process, consisting in context-activity-outcome dynamics, where the activity includes analysis and synthesis and the outcome is an object design. And let's run with the idea that dramatization is a scenario-process, where the activity consists in performances and where the outcome is the audience's experience of a show. So, setting these ideas beside one another suggests that object designs and shows are analogous as they are both outcomes of a public organization's scenario-processes.

Marshall: I like the method, and I follow the reasoning. Why not push the object design-show analogy further, to see where it takes us.

Petra: A question to consider would then be: how are object designs similar to shows?

Marshall: That's a good step. And how are they similar?

Petra: They are both purposeful phenomena.

Marshall: Okay, but subordinating two ideas to the same broader category doesn't in itself say how they are similar.

Petra: True, but I've come to have ideas about what are purposeful phenomena: in particular, they are functioning wholes, whether they are physically or digitally embodied systems, or not. The idea that objects are functioning wholes is clearly conventional, and much the same is true of their representations, namely as object-designs. We don't normally refer to shows as functioning wholes, but we do speak of shows "holding together," or not, as the case may be. Aren't shows functioning wholes, even as they are experiential?

Nora: We know what fits together in an object: it's the features. What is it that holds together in a show?

Petra: The characters' performances.

Nora: What holds the performances together? It's not their physical organization!

Petra: The scene, the character-relationships, and the narrative arc of the show come to mind.

Nora: I'm now seeing the analogy. What do you want to do with it?

Petra: Well, we have the idea that designing eventuates in object-designs, can't 
we extend that idea to say that sometimes designing eventuates in shows, or designs for them?

Nora: Well, I see there's some concept resonance there. Do you have any illustrations to offer?

Petra: Well, how about a strategic planning project? Isn't the scenario-process outcome something like a show, constituted by performances by such characterroles as planners or project teams, put on for an audience of decision-makers?

Nora: That rings true. So what implications does that reasoning hold for theorizing design-projects in public organizations?

Petra: The implication is that the object-designs eventuating from designing within design-projects can be systems or shows. Thinking of design-project outcomes as shows will make theories of dramatization as relevant to professional practice as putting on performances is central to professional life.

Marshall: Petra, you've just put on a winning show! Love it!

(Nora and Olivier applaud.)

Marshall: You might wonder why this all sounds so original. The answer is that the Harvard approach to management didn't bring dramatization into its purposive theorizing, even as it was central to student life in a case-teaching tradition. Meanwhile, Simon's approach stuck with the idea that decision-making in organizations was about search for information, making arguments, and exercising decision-making authority. And further, Goffman's ideas were seen as mainly useful as ways to counter the Simon approach to decision-making, rather than as something that could be melded with his ideas about artificial phenomena and designing.

Olivier: Do you think we should sum up?

Petra: I think we should still stare at these ideas about management, designing, and dramatization as if they are a challenging work of art, at least for the time being.

Nora: I think Petra's right, Olivier.

Marshall: Thanks everyone; let's meet later this week to do some creative thinking about the role of case studies. ...

\section{NOTES}

1 Fayol (1919/1984), Porter (1985), Goodman (2000), Sarasvathy (2008).

2 Pawson and Tilley (1997), Stake (2010), Funnell and Rogers (2011).

3 Craver and Darden (2013).

4 Simon (1996), Dym (1994), Cross (2008).

5 Abbott $(2001,2016)$.

6 Rescher (1996).

7 Moore (1995).

8 Bryson (2018).

9 Simon (1996). 